\title{
Growth and characterization of dilute nitride GaNxP1-x nanowires and GaNxP1-x/GaNyP1-y core/shell nanowires on Si (111) by gas source molecular beam epitaxy
}

S. Sukrittanon, Y. J. Kuang, Alexandr Dobrovolsky, Won-Mo Kang, Ja-Soon Jang, BongJoong Kim, Weimin Chen, Irina Buyanova and C. W. Tu

\section{Linköping University Post Print}

\section{Tweet}

N.B.: When citing this work, cite the original article.

Original Publication:

S. Sukrittanon, Y. J. Kuang, Alexandr Dobrovolsky, Won-Mo Kang, Ja-Soon Jang, Bong-Joong Kim, Weimin Chen, Irina Buyanova and C. W. Tu, Growth and characterization of dilute nitride GaNxP1-x nanowires and GaNxP1-x/GaNyP1-y core/shell nanowires on Si (111) by gas source molecular beam epitaxy, 2014, Applied Physics Letters, (105), 7, 072107.

http://dx.doi.org/10.1063/1.4893745

Copyright: American Institute of Physics (AIP) http://www.aip.org/

Postprint available at: Linköping University Electronic Press http://urn.kb.se/resolve?urn=urn:nbn:se:liu:diva-109928 


\section{AIP Applied Physics Letters}

\section{Growth and characterization of dilute nitride GaNxP1-x nanowires and GaNxP1-x/GaNyP1-y core/shell nanowires on $\mathrm{Si}(111)$ by gas source molecular beam epitaxy \\ S. Sukrittanon, Y. J. Kuang, A. Dobrovolsky, Won-Mo Kang, Ja-Soon Jang, Bong-Joong Kim, W. M. Chen, I. A. Buyanova, and C. W. Tu}

Citation: Applied Physics Letters 105, 072107 (2014); doi: 10.1063/1.4893745

View online: http://dx.doi.org/10.1063/1.4893745

View Table of Contents: http://scitation.aip.org/content/aip/journal/apl/105/7?ver=pdfcov

Published by the AIP Publishing

\section{Articles you may be interested in}

A geometrical model for the description of the AIN shell morphology in GaN-AIN core-shell nanowires

J. Appl. Phys. 114, 244305 (2013); 10.1063/1.4854495

Micro-Raman investigations of InN-GaN core-shell nanowires on $\mathrm{Si}$ (111) substrate

AlP Advances 3, 062114 (2013); 10.1063/1.4811365

Critical shell thickness for InAs-AlxIn1-x As(P) core-shell nanowires

J. Appl. Phys. 112, 124305 (2012); 10.1063/1.4769735

High efficiency ultraviolet emission from AlxGa1-xN core-shell nanowire heterostructures grown on Si (111) by molecular beam epitaxy

Appl. Phys. Lett. 101, 043115 (2012); 10.1063/1.4738983

Growth and photoluminescence of self-catalyzed GaP/GaNP core/shell nanowires on $\mathrm{Si}(111)$ by gas source molecular beam epitaxy

Appl. Phys. Lett. 100, 053108 (2012); 10.1063/1.3681172

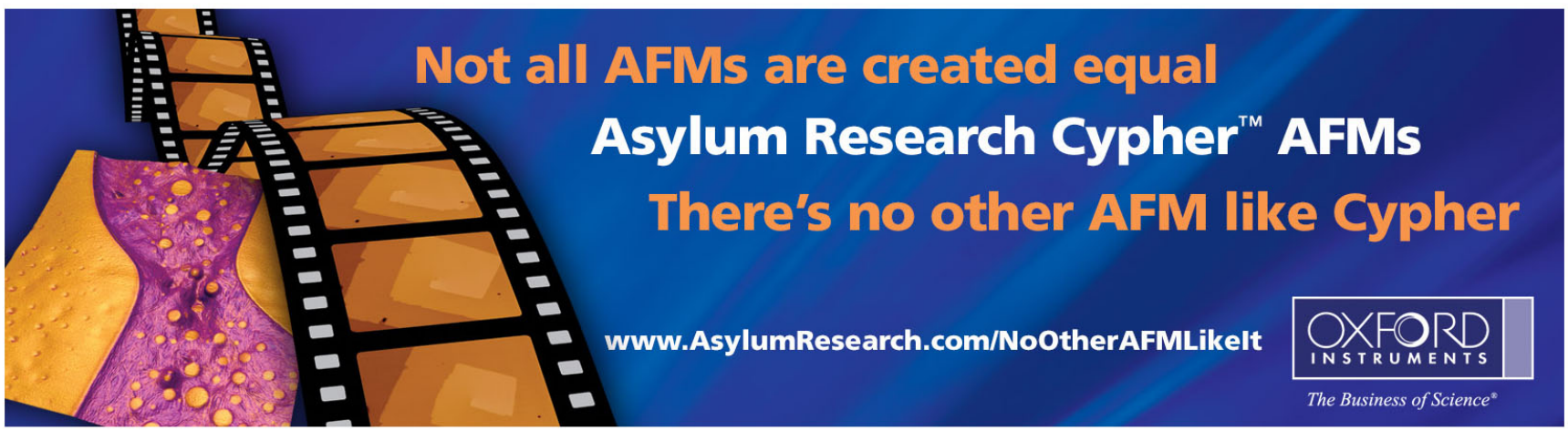




\title{
Growth and characterization of dilute nitride $\mathrm{GaN}_{\mathrm{x}} \mathrm{P}_{1-\mathrm{x}}$ nanowires and $\mathrm{GaN}_{\mathrm{x}} \mathrm{P}_{1-\mathrm{x}} / \mathrm{GaN}_{\mathrm{y}} \mathrm{P}_{1-\mathrm{y}}$ core/shell nanowires on $\mathrm{Si}(111)$ by gas source molecular beam epitaxy
}

\author{
S. Sukrittanon, ${ }^{1}$ Y. J. Kuang (广户彦瑾), ${ }^{2}$ A. Dobrovolsky, ${ }^{3}$ Won-Mo Kang, ${ }^{4}$ Ja-Soon Jang, ${ }^{5}$ \\ Bong-Joong Kim, ${ }^{4}$ W. M. Chen, ${ }^{3}$ I. A. Buyanova, ${ }^{3}$ and C. W. Tu ${ }^{1,6}$ \\ ${ }^{1}$ Graduate Program of Material Science and Engineering, University of California, San Diego, La Jolla, \\ California 92037, USA \\ ${ }^{2}$ Department of Physics, University of California, San Diego, La Jolla, California 92037, USA \\ ${ }^{3}$ Department of Physics, Chemistry and Biology, Linköping University, 58183 Linköping, Sweden \\ ${ }^{4}$ Department of Materials Science and Engineering, Gwangju institute of Science and Technology (GIST), \\ Gwangju 500-712, South Korea \\ ${ }^{5}$ Department of Electronic Engineering, LED-IT Fusion Technology Research Center, Yeungnam University, \\ Daegu 712-749, South Korea \\ ${ }^{6}$ Department of Electrical and Computer Engineering, University of California, San Diego, La Jolla, \\ California 92037, USA
}

(Received 28 April 2014; accepted 11 August 2014; published online 20 August 2014)

\begin{abstract}
We have demonstrated self-catalyzed $\mathrm{GaN}_{\mathrm{x}} \mathrm{P}_{1-\mathrm{x}}$ and $\mathrm{GaN}_{\mathrm{x}} \mathrm{P}_{1-\mathrm{x}} / \mathrm{GaN}_{\mathrm{y}} \mathrm{P}_{1-\mathrm{y}}$ core/shell nanowire growth by gas-source molecular beam epitaxy. The growth window for $\mathrm{GaN}_{\mathrm{x}} \mathrm{P}_{1-\mathrm{x}}$ nanowires was observed to be comparable to that of $\mathrm{GaP}$ nanowires $\left(\sim 585^{\circ} \mathrm{C}\right.$ to $\left.\sim 615^{\circ} \mathrm{C}\right)$. Transmission electron microscopy showed a mixture of cubic zincblende phase and hexagonal wurtzite phase along the [111] growth direction in $\mathrm{GaN}_{\mathrm{x}} \mathrm{P}_{1-\mathrm{x}}$ nanowires. A temperature-dependent photoluminescence (PL) study performed on $\mathrm{GaN}_{\mathrm{x}} \mathrm{P}_{1-\mathrm{x}} / \mathrm{GaN}_{\mathrm{y}} \mathrm{P}_{1-\mathrm{y}}$ core/shell nanowires exhibited an $\mathrm{S}$-shape dependence of the PL peaks. This suggests that at low temperature, the emission stems from N-related localized states below the conduction band edge in the shell, while at high temperature, the emission stems from band-to-band transition in the shell as well as recombination in the $\mathrm{GaN}_{\mathrm{x}} \mathrm{P}_{1-\mathrm{x}}$ core. (C) 2014 AIP Publishing LLC. [http://dx.doi.org/10.1063/1.4893745]
\end{abstract}

In recent years, III-V semiconductor nanowires grown on $\mathrm{Si}$ substrate have been considered to be very promising nanoscale structures for various applications because they combine the superior properties of III-V materials with the inexpensive cost of $\mathrm{Si}$. In solar cell applications, III-V nanowire arrays provide an additional benefit of increasing light absorption over conventional thin film configurations by allowing multiple passes of light through the nanowire materials. ${ }^{1,2}$ Furthermore, the light absorption and carrier extraction direction can be decoupled by employing core/shell nanowire structures: ${ }^{3}$ nanowires can be elongated to increase photon absorption pathway while the radial junction can be kept smaller than the minority carrier diffusion length to suppress recombination. Nanowires also open up the market for light-weight, portable, and flexible solar cells by, for example, embedding nanowires into flexible polymers and lifting them off from the substrate to a flexible substrate. ${ }^{4,5}$

Our study focuses on dilute nitride $\mathrm{GaN}_{\mathrm{x}} \mathrm{P}_{1-\mathrm{x}} / \mathrm{GaN}_{\mathrm{y}} \mathrm{P}_{1-\mathrm{y}}$ core/shell nanowires. $\mathrm{GaN}_{\mathrm{x}} \mathrm{P}_{1-\mathrm{x}} / \mathrm{GaN}_{\mathrm{y}} \mathrm{P}_{1-\mathrm{y}}$ has a type-II band alignment, which can assist electron-hole pair radial separation across the heterojunction. We can tune bandgap absorption in the core and shell for optimal solar photon absorption. $^{6}$

The strong interaction between $\mathrm{N}$-localized states and the matrix extended states split the conduction band into two bands, $\mathrm{E}_{+}$and $\mathrm{E}_{-}{ }^{7}$ moving upward and downward in energy, respectively. Thus, incorporating a small amount of $\mathrm{N}$ into a III-V host significantly decreases the bandgap $\left(\mathrm{E}_{-}\right)^{8,9}$ and leads to many proposals to use dilute nitrides in optical and electrical devices. ${ }^{10-13}$ In particular, $\sim 0.5 \%$ of $\mathrm{N}$ incorporation changes the bandgap from indirect to direct in $\mathrm{GaN}_{\mathrm{x}} \mathrm{P}_{1-\mathrm{x}} \cdot{ }^{14,15}$ According to our previous study, $\mathrm{N}$ can be incorporated into GaP up to $16 \%,{ }^{8}$ which makes $\mathrm{GaN}_{\mathrm{x}} \mathrm{P}_{1-\mathrm{x}}$ tunable from $1.22 \mathrm{eV}$ to $2.15 \mathrm{eV}$, covering a wide range of the solar spectrum.

To obtain the optimal solar efficiency of this promising material, a solar cell simulation software EtaOpt was employed. EtaOpt uses the detailed balance limit of efficiency to evaluate the potential power output of solar cells and then compare the performance among various bandgap structures. ${ }^{16}$ An ideal condition is assumed in the EtaOpt simulation: (i) All photons with $\mathrm{E}>\mathrm{E}_{\mathrm{g}}$ are absorbed and (ii) each absorbed photon creates an electron-hole pair. In our simulation, the AM 1.5d (direct) spectrum was set to illuminate the dual junction of various bandgap structures at $300 \mathrm{~K}$. The variation of the bandgaps was limited to the $\mathrm{GaN}_{\mathrm{x}} \mathrm{P}_{1-\mathrm{x}}$ tunable range. The result showed that the optimal efficiency of $\mathrm{GaN}_{\mathrm{x}} \mathrm{P}_{1-\mathrm{x}} / \mathrm{GaN}_{\mathrm{y}} \mathrm{P}_{1-\mathrm{y}}$ core/shell nanowires can be $\sim 44 \%$, with $9 \%[\mathrm{~N}]$ cores and $1 \%[\mathrm{~N}]$ shells.

Our previous study demonstrated that self-catalyzed vertical GaP nanowires can be expitaxially grown on $\mathrm{Si}$ (111) by gas-source molecular beam epitaxy (GSMBE). ${ }^{17,18} \mathrm{GaP}$ nanowires have a growth window from $\sim 585^{\circ} \mathrm{C}$ to $\sim 615^{\circ} \mathrm{C}$. ${ }^{17}$ The low-temperature limit is set by the low surface mobility of Ga adatoms, while the high temperature limit is set by unattainable supersaturation conditions of vapor-liquid-solid (VLS) growth. However, we could not grow dilute nitride $\mathrm{GaN}_{\mathrm{x}} \mathrm{P}_{1-\mathrm{x}}$ nanowires on $\mathrm{Si}$ (111) under RF-plasma activated $\mathrm{N}$ ambient at substrate temperatures $\left(\mathrm{T}_{\text {sub }}\right) 520^{\circ} \mathrm{C},{ }^{18}$ which was lowered to 
incorporate N. It is suspected that this failure was the result of low Ga mobility.

In this paper, we demonstrate that self-catalyzed $\mathrm{GaN}_{\mathrm{x}} \mathrm{P}_{1-\mathrm{x}}$ nanowires and $\mathrm{GaN}_{\mathrm{x}} \mathrm{P}_{1-\mathrm{x}} / \mathrm{GaN}_{\mathrm{y}} \mathrm{P}_{1-\mathrm{y}}$ core/shell nanowires $(\mathrm{x}<\mathrm{y})$ can be grown on $\mathrm{Si}$ (111) substrate via GSMBE. The $\mathrm{T}_{\text {sub }}$ was increased to boost $\mathrm{Ga}$ adatom mobility to satisfy the conditions for VLS growth mechanism, and $\mathrm{N}$ plasma was ignited after growth started. The structural properties of the nanowires were characterized using scanning electron microscopy (SEM) and transmission electron microscopy (TEM). Their optical properties were characterized using temperature-dependent photoluminescence (PL) measurements.

The samples reported in this paper were grown in a Varian Gen-II MBE system modified to handle gas sources. Thermally cracked $\mathrm{PH}_{3}$ at $100{ }^{\circ} \mathrm{C}$ was used as the $\mathrm{P}_{2}$ source, while elemental $\mathrm{Ga}$ was used to generate a $\mathrm{Ga}$ atomic beam through an effusion cell. Prior to growth, the $\mathrm{Si}$ (111) substrate was dipped in an HF solution at room temperature (RT) for 10 $\mathrm{s}$ to remove the intrinsic oxide, and then rinsed with deionized water. The substrate was then treated in $30 \% \mathrm{KOH}$ at $80^{\circ} \mathrm{C}$ for $20 \mathrm{~s}$ to expose a fresh $\mathrm{Si}$ surface and then rinsed with methanol. The substrate was again dipped in an HF solution for $10 \mathrm{~s}$ and then rinsed with deionized water. The substrate was finally blow-dried with a $\mathrm{N}_{2}$ gun, and immediately loaded into the load-lock chamber. In the growth chamber, the substrate was heated to $\sim 710^{\circ} \mathrm{C}$ for $15 \mathrm{~min}$ for thermal cleaning, and then $\mathrm{T}_{\text {sub }}$ was decreased to the growth temperature.

For $\mathrm{GaN}_{\mathrm{x}} \mathrm{P}_{1-\mathrm{x}}$ nanowire growth, $\mathrm{Ga}$ atoms were deposited as catalysts on the $\mathrm{Si}$ (111) substrate for $30 \mathrm{~s}$ with a Ga flux of $\sim 0.7$ monolayer/s, calibrated by Ga-induced reflection high energy electron diffraction (RHEED) intensity oscillation for the planar growth of $\mathrm{GaP}$ under the same $\mathrm{T}_{\text {sub. }}{ }^{19}$ The $\mathrm{P}$ incorporation rate was calibrated by $\mathrm{P}$-induced RHEED oscillations on a surface with excess Ga adatoms. ${ }^{19}$ The substrate was then annealed for $30 \mathrm{~s}$ to form Ga seed droplets. Growth started by opening the Ga shutter and injecting $\mathrm{PH}_{3}$ through a hydride injector into the growth chamber to initiate growth of GaP nanowires. After $90 \mathrm{~s}$ of growth, RF N plasma, excited at $13.56 \mathrm{MHz}$, was then ignited. The $\mathrm{GaN}_{\mathrm{x}} \mathrm{P}_{1-\mathrm{x}}$ nanowires were grown under the VLS mechanism for 15 min with a V/III incorporation ratio of $\sim 2.5$. To ensure uniformity, the substrate was rotated at 5 RPM during growth. To study the growth window of $\mathrm{GaN}_{\mathrm{x}} \mathrm{P}_{1-\mathrm{x}}$ nanowires, $\mathrm{T}_{\text {sub }}$ was set to $\sim 515^{\circ} \mathrm{C}, \sim 585^{\circ} \mathrm{C}$, $\sim 600^{\circ} \mathrm{C}, \sim 615^{\circ} \mathrm{C}$, and $\sim 630^{\circ} \mathrm{C}$, henceforth referred to as S-515, S-585, S-600, S-615, and S-630, respectively.

For $\mathrm{GaN}_{\mathrm{x}} \mathrm{P}_{1-\mathrm{x}} / \mathrm{GaN}_{\mathrm{y}} \mathrm{P}_{1-\mathrm{y}}$ core/shell nanowires, henceforth referred to as $\mathrm{S}-\mathrm{GaNP} / \mathrm{GaNP}$, the $\mathrm{GaN}_{\mathrm{x}} \mathrm{P}_{1-\mathrm{x}}$ cores were grown at $\sim 615^{\circ} \mathrm{C}$, as was done for $\mathrm{S}-615$, using the procedure described above. Subsequently, for the shells, $\mathrm{T}_{\text {sub }}$ was decreased to $\sim 450^{\circ} \mathrm{C}$, the $\mathrm{V} / \mathrm{III}$ incorporation ratio was increased to $\sim 3.5$ by increasing the $\mathrm{PH}_{3}$ flow rate, and the shells were grown for $15 \mathrm{~min}$. Decreasing $\mathrm{T}_{\text {sub }}$ and increasing the $\mathrm{V} / \mathrm{III}$ incorporation ratio reduce Ga adatom mobility on the growing surface. This decreased mobility suppresses the VLS mechanism, which decreases axial growth rate, and, instead, promotes the radial growth rate through step-mediated growth mode. $^{20,21}$ Lowering the $\mathrm{T}_{\text {sub }}$ facilitates $\mathrm{N}$ incorporation; ${ }^{14}$ hence, a higher $\mathrm{N}$ composition is expected in the shell.
The VLS growth mechanism, suggested by Wagner in $1964,{ }^{22}$ has been widely used to explain the growth of nanowires. In this mechanism, liquid catalyst droplets absorb vapor components and become alloy droplets. The droplets are then further supersaturated, driving the precipitation of the component at the liquid-solid interface to achieve minimum free energy of the alloy system. During $\mathrm{GaN}_{\mathrm{x}} \mathrm{P}_{1-\mathrm{x}}$ nanowire growth, there is a competition between the nucleation rate at the droplet/Si interface and at the Si substrate surface. According to our previous study, ${ }^{18}$ dilute nitride $\mathrm{GaN}_{\mathrm{x}} \mathrm{P}_{1-\mathrm{x}}$ nanowires cannot be grown under RF-plasmaactivated $\mathrm{N}$ ambient. One possible reason is that the activated $\mathrm{N}$ ambient increases the nucleation rate at the substrate surface, such that it is comparable to the nucleation rate at the droplet/Si interface, resulting in planar formation of $\mathrm{GaN}_{\mathrm{x}} \mathrm{P}_{1-\mathrm{x}}$ instead of nanowires. In contrast, in this study, we initiated growth of $\mathrm{GaP}$ nanowires first and then activated $\mathrm{N}$ plasma to grow $\mathrm{GaN}_{\mathrm{x}} \mathrm{P}_{1-\mathrm{x}}$ nanowires. SEM images (Figures 1(a)-1(c)) show that $\mathrm{GaN}_{\mathrm{x}} \mathrm{P}_{1-\mathrm{x}}$ nanowires were grown vertically on a $\mathrm{Si}$ (111) substrate. By first growing the GaP nanowire seeding roots, the nucleation rate of $\mathrm{GaN}_{\mathrm{x}} \mathrm{P}_{1-\mathrm{x}}$ at the $\mathrm{Ga}$ droplet/GaP interface is higher compared to that at the $\mathrm{Si}$ surface, resulting in the formation of $\mathrm{GaN}_{\mathrm{x}} \mathrm{P}_{1-\mathrm{x}}$ nanowires.

With regard to $\mathrm{GaN}_{\mathrm{x}} \mathrm{P}_{1-\mathrm{x}}$ nanowires, only S-585, S-600, and S-615 were grown. This indicates that the growth window of $\mathrm{GaN}_{\mathrm{x}} \mathrm{P}_{1-\mathrm{x}}$ nanowires is from $\mathrm{T}_{\text {sub }} \sim 585^{\circ} \mathrm{C}$ to $\mathrm{T}_{\text {sub }} \sim 615^{\circ} \mathrm{C}$, comparable to the growth window of $\mathrm{GaP}$ nanowires. ${ }^{17}$ As $\mathrm{T}_{\text {sub }}$ increases $\left(\sim 585^{\circ} \mathrm{C}, \sim 600^{\circ} \mathrm{C}\right.$, and $\sim 615^{\circ} \mathrm{C}$ ), the average diameter of nanowires decreases $(92 \pm 13 \mathrm{~nm}, 67 \pm 5 \mathrm{~nm}$, and $65 \pm 9 \mathrm{~nm}$, respectively), while the average length increases $(0.4 \pm 0.1 \mu \mathrm{m}, 0.7 \pm 0.1 \mu \mathrm{m}$, $2.2 \pm 0.1 \mu \mathrm{m}$, respectively). This trend is in line with the explanation detailed in our previous paper for GaP nanowires. ${ }^{17}$ Below the growth window (S-515), the short Ga adatom diffusion length on the surface impedes VLS growth. Conversely, above the growth window (S-630), only a small amount of vapor can dissolve into Ga droplets and contribute to VLS growth.

Among our $\mathrm{GaN}_{\mathrm{x}} \mathrm{P}_{1-\mathrm{x}}$ nanowire samples, $\mathrm{S}-615$ has the highest density ranging from $\sim 4 \times 10^{8} \mathrm{~cm}^{-2}$ to $\sim 1.2 \times$ $10^{9} \mathrm{~cm}^{-2}$ across the substrate with an axial growth rate of $\sim 150 \mathrm{~nm} / \mathrm{min}$. Consequently, the growth conditions of S-615 were employed to grow the core of S-GaNP/GaNP. For S-GaNP/GaNP (Figure 1(d)), the average diameter and length of the nanowires are $115 \pm 4 \mathrm{~nm}$ and $2.3 \pm 0.2 \mu \mathrm{m}$, respectively. After the shell was grown, the average diameter increased by $\sim 80 \%$ with no significant increase in length.

For further structural analyses, TEM experiments were performed on S-615 using an FEI-Tecnai microscope operating at $300 \mathrm{keV}$. The crystal structure of $\mathrm{GaN}_{\mathrm{x}} \mathrm{P}_{1-\mathrm{x}}$ nanowires features random twins and stacking faults between cubic zincblende (ZB) and hexagonal wurtzite (WZ) phases along the [111] nanowire growth direction as shown in Figures 2(a)-2(c). This mixture of the two structures are also observed in GaP nanowires, ${ }^{17} \mathrm{GaP} / \mathrm{GaNP}$ core/shell nanowires, ${ }^{17}$ and other III-V semiconductors with moderate iconicity values due to the small difference in formation energies between $\mathrm{ZB}$ and $\mathrm{WZ}$ phases. ${ }^{23}$ However, based on our examination, the majority phase of $\mathrm{GaN}_{\mathrm{x}} \mathrm{P}_{1-\mathrm{x}}$ nanowires is still $\mathrm{ZB}$, which is also favored by $\mathrm{GaN}_{\mathrm{x}} \mathrm{P}_{1-\mathrm{x}}$ thin films. ${ }^{24}$ Figure $2(\mathrm{~d})$ shows the 


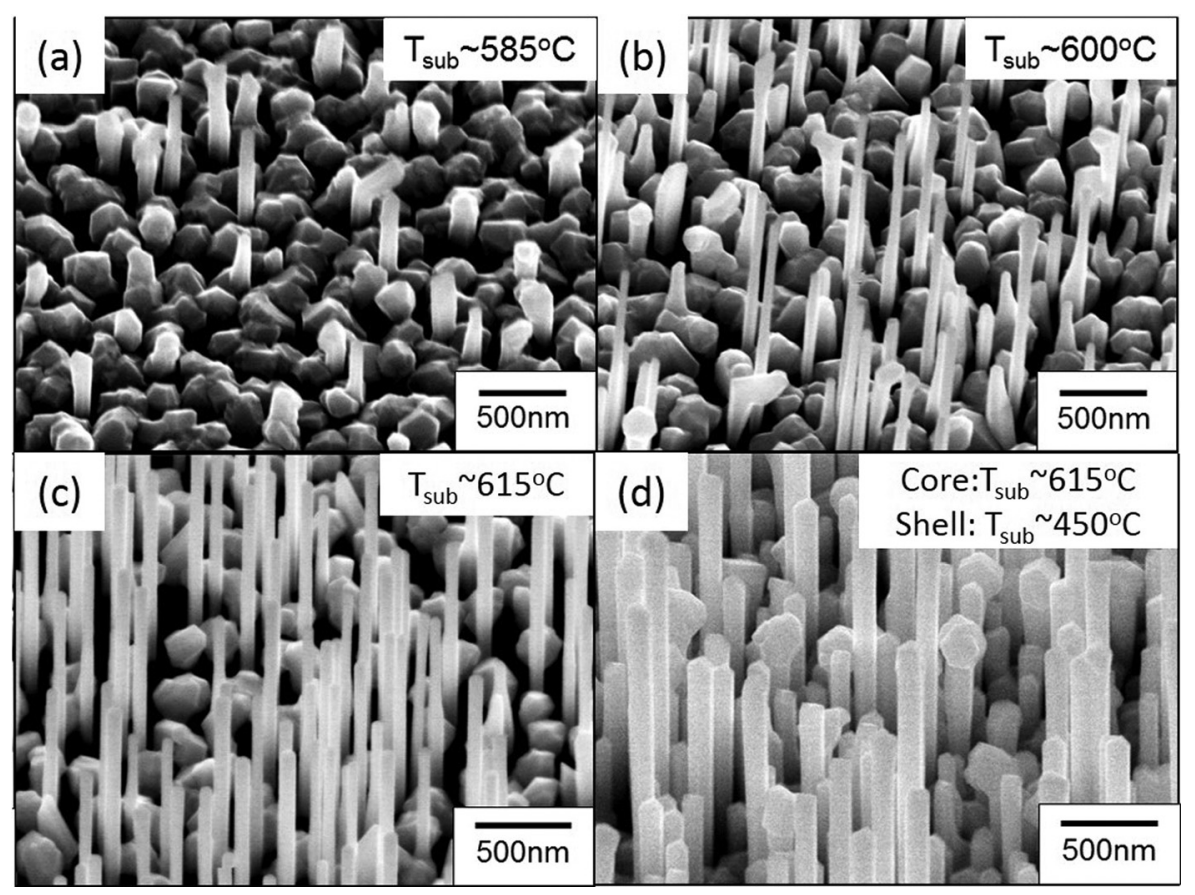

FIG. 1. SEM images of (a) $\mathrm{GaN}_{\mathrm{x}} \mathrm{P}_{1-\mathrm{x}}$ nanowires on $\mathrm{Si}(111)$ at $\mathrm{T}_{\text {sub }} \sim 585^{\circ} \mathrm{C}$ (S-585), (b) $\mathrm{T}_{\text {sub }} \sim 600^{\circ} \mathrm{C}$ (S-600), (c) $\mathrm{T}_{\text {sub }} \sim 615^{\circ} \mathrm{C} \quad(\mathrm{S}-615)$, and (d) $\mathrm{GaN}_{\mathrm{x}} \mathrm{P}_{1-\mathrm{x}} / \mathrm{GaN}_{\mathrm{y}} \mathrm{P}_{1-\mathrm{y}}$ core/shell nanowires on $\mathrm{Si}(111)$ at $\mathrm{T}_{\text {sub }} \sim 615^{\circ} \mathrm{C}$ for $\mathrm{GaN}_{\mathrm{x}} \mathrm{P}_{1-\mathrm{x}}$ core and $450^{\circ} \mathrm{C}$ for $\mathrm{GaN}_{\mathrm{y}} \mathrm{P}_{1-\mathrm{y}}$ shell $(\mathrm{S}-\mathrm{GaNP} / \mathrm{GaNP})$.

high resolution electron microscopy image of the boxed region of Figure 2(a). This clearly presents that both structures existthe upper and lower halves are associated with $\mathrm{WZ}$ and $\mathrm{ZB}$ phases, respectively, as clarified by the fast Fourier transformation image located at each area. Interestingly, the twins were found to appear only in $\mathrm{ZB}$ structure.

For optical studies, PL measurements were carried out in a variable temperature cryostat on S-615, S-GaNP/GaNP as well as on $\mathrm{GaP} / \mathrm{GaN}_{\mathrm{y}} \mathrm{P}_{1-\mathrm{y}}$ core/shell nanowires (S-GaP/ GaNP), for which the shell was grown using the same conditions as the shell of $\mathrm{S}-\mathrm{GaNP} / \mathrm{GaNP}$. $\mathrm{N}$ incorporation in the

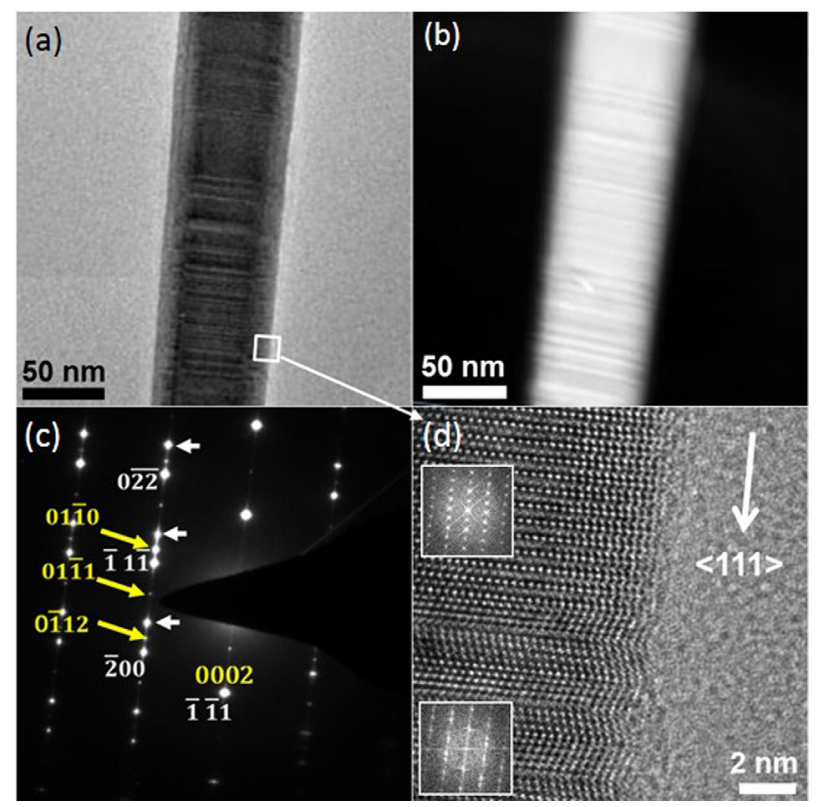

FIG. 2. TEM images of $\mathrm{GaN}_{\mathrm{x}} \mathrm{P}_{1-\mathrm{x}}$ core nanowires (S-615). (a)-(b) Zincblende and Wurzite phases are formed in parallel in individual nanowires. (c) In transmission electron diffraction (TED) pattern, twin spots are indicated by white arrows, and Zincblende and Wurzite spots are indexed in white and yellow, respectively. (d) High resolution electron microscopy image showing $\mathrm{ZB}$ and $\mathrm{WZ}$ structures with corresponding fast furrier transformation images. shell layers of both $\mathrm{S}-\mathrm{GaNP} / \mathrm{GaNP}$ and $\mathrm{S}-\mathrm{GaP} / \mathrm{GaNP}$ was expected to be comparable. All samples were excited by a pulsed Ti:sapphire picosecond laser with a photon wavelength of $410 \mathrm{~nm}$ and a pulse repetition frequency of $76 \mathrm{MHz}$, and PL was detected using a streak camera system. The measurements were performed on as-grown nanowire arrays.

Figure 3 summarizes the results of PL measurements at $4 \mathrm{~K}$ and $300 \mathrm{~K}$, performed on S-615, S-GaNP/GaNP and $\mathrm{S}-\mathrm{GaP} / \mathrm{GaNP}$. With respect to the emission at $4 \mathrm{~K}$

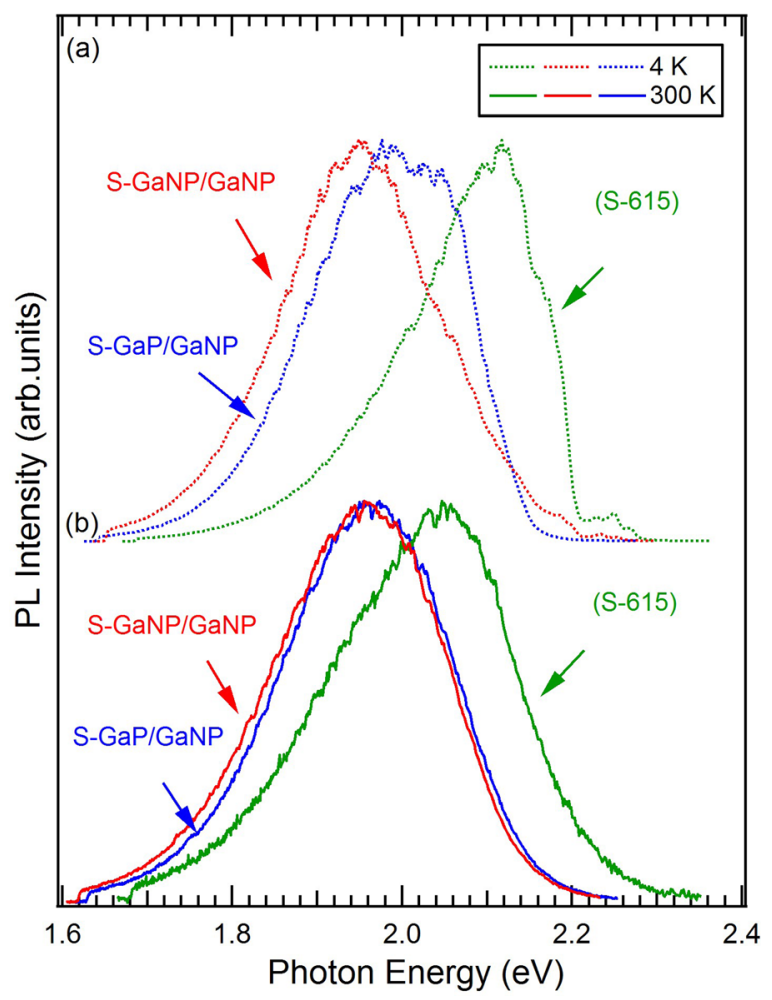

FIG. 3. PL emission from arrays of $\mathrm{GaN}_{\mathrm{x}} \mathrm{P}_{1-\mathrm{x}}$ nanowires $(\mathrm{S}-615), \mathrm{GaN}_{\mathrm{x}} \mathrm{P}_{1-\mathrm{x}}$ / $\mathrm{GaN}_{\mathrm{y}} \mathrm{P}_{1-\mathrm{y}}$ core/shell nanowires $(\mathrm{S}-\mathrm{GaNP} / \mathrm{GaNP})$, and $\mathrm{GaP} / \mathrm{GaN}_{\mathrm{y}} \mathrm{P}_{1-\mathrm{y}}$ core/ shell nanowires (S-GaP/GaNP) performed at (a) $4 \mathrm{~K}$ and (b) $300 \mathrm{~K}$. 
(Figure 3(a)), the PL emission shows single PL peaks for nanowires (S-615) and both core/shell nanowires (S-GaNP/ GaNP and $\mathrm{S}-\mathrm{GaP} / \mathrm{GaNP}$ ). Both the single PL peaks of S-GaNP/GaNP and S-GaP/GaNP are believed to come from their shells, as a result of fast diffusion of photo-excited electrons from the core to the shell with lower conduction band edge for S-GaNP/GaNP, and as a result of insignificant emission from the indirect $\mathrm{GaP}$ core for $\mathrm{S}-\mathrm{GaP} / \mathrm{GaNP}$, respectively. It should be noted that the PL peak of S-GaNP/GaNP unexpectedly shows at lower energy than that of S-GaP/ GaNP, which is believed to be attributed to the effects of slight variation of $\mathrm{N}$ incorporation $(\sim 0.2 \%)$ between the shells of the two samples. With regard to S-615, the higher energy PL peak is attributed to lower $\mathrm{N}$ incorporation in the core $([\mathrm{N}] \sim 1 \%)$ relative to the shell $([\mathrm{N}] \sim 2 \%)$ based on studies of PL emission vs. $\mathrm{N},{ }^{25,26}$ in which an increase in [N] causes a red-shift of the PL emission.

With respect to the emission at $300 \mathrm{~K}$ (Figure 3(b)), it was expected that each of the PL emissions would experience a red-shift relative to the PL emission at $4 \mathrm{~K}$ according to the Varshni relation. ${ }^{27}$ The red-shift was observed for S-615 and S-GaP/GaNP but not for S-GaNP/GaNP. This suggests that the PL emission of S-GaNP/GaNP could be composed of two components at high temperature: contribution from the shell and contribution from the core. To further understand about this dual-component contribution, the temperature-dependent PL measurement was performed on S-GaNP/GaNP.

Figure 4 shows temperature-dependent PL emission of S-GaNP/GaNP. The PL peak position indicates the so-called $S$-shape behavior, i.e., a red shift with increasing temperature

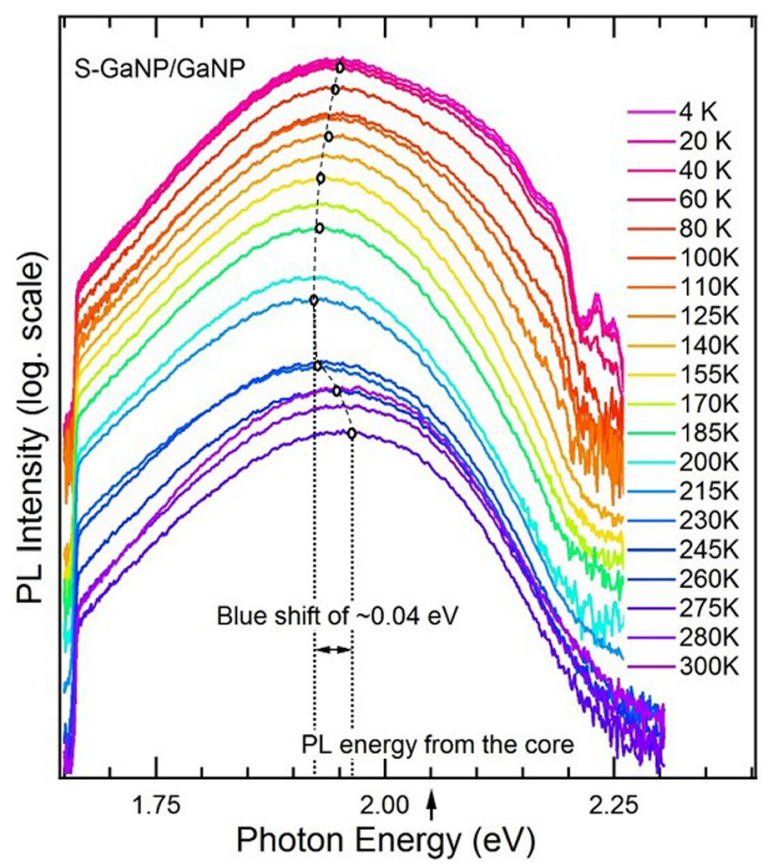

FIG. 4. Temperature-dependent PL emission of $\mathrm{GaN}_{\mathrm{x}} \mathrm{P}_{1-\mathrm{x}} / \mathrm{GaN}_{\mathrm{y}} \mathrm{P}_{1-\mathrm{y}}$ core/ shell nanowires ( $\mathrm{S}-\mathrm{GaNP} / \mathrm{GaNP}$ ) exhibiting the $\mathrm{S}$-shape behavior, which has the blue shift of $0.04 \mathrm{eV}$. At low temperature, the emission of $\mathrm{GaN}_{\mathrm{x}} \mathrm{P}_{1-\mathrm{x}}$ / $\mathrm{GaN}_{\mathrm{y}} \mathrm{P}_{1-\mathrm{y}}$ core/shell nanowires is from N-related-localized states below the conduction band edge in the shell. At high temperature, the emission comes from band-to-band radiation recombination in the shell layer and PL emission, peaking at $2.05 \mathrm{eV}$, from the core layer. at low temperatures followed by a blue shift at higher temperatures. This behavior is a signature behavior of dilute nitride materials ${ }^{28-31}$ and can be understood as follows. At low temperature $(\sim 10 \mathrm{~K})$, the emission of S-GaNP/GaNP comes from various $\mathrm{N}$-related-localized states below the conduction band edge in the shell, similar to the emission in planar $\mathrm{GaN}_{\mathrm{x}} \mathrm{P}_{1-\mathrm{x}}{ }^{25,28}$ and $\mathrm{GaP} / \mathrm{GaN}_{\mathrm{y}} \mathrm{P}_{1-\mathrm{y}}$ core/shell nanowires. ${ }^{32,33}$ As temperature increases, a red shift is observed. This red shift reflects thermal depopulation of the N-related-localized states, which starts from the states that are shallowest in energy (i.e., correspond to high energy PL components). ${ }^{25,28,32}$ As the temperature is further increased above $230 \mathrm{~K}$, the appearance of an additional PL component peaking at higher energy causes a blue shift of the PL peak. This new PL component can be related to thermal activation of (i) band-to-band emission from the $\mathrm{GaN}_{\mathrm{y}} \mathrm{P}_{1-\mathrm{y}}$ shell or/and (ii) emission from the higher energy $\mathrm{GaN}_{\mathrm{x}} \mathrm{P}_{1-\mathrm{x}}$ core. To distinguish between these two possibilities, temperature-dependent $\mathrm{PL}$ measurements were also performed on $\mathrm{S}-\mathrm{GaP} / \mathrm{GaNP}$ to eliminate the possibility of the emission from the core.

The temperature-dependent PL emission of S-GaP/ GaNP also exhibits S-shape behavior, which is very similar to the PL emission of S-GaNP/GaNP. Temperature increase above $220 \mathrm{~K}$ again causes activation of the weak PL component peaking at higher energy resulting in a blue shift of the PL peak position. Since the indirect-bandgap GaP core does not significantly emit, this PL component corresponds to band-to-band emission from the $\mathrm{GaN}_{\mathrm{y}} \mathrm{P}_{1-\mathrm{y}}$ shell. To compare the PL emission between S-GaP/GaNP and S-GaNP/ $\mathrm{GaNP}$, it is noted that the S-shape behavior in $\mathrm{S}-\mathrm{GaP} / \mathrm{GaNP}$ (a blue shift of $0.02 \mathrm{eV}$ ) is less pronounced than the S-shape behavior in $\mathrm{S}-\mathrm{GaNP} / \mathrm{GaNP}$ (a blue shift of $0.04 \mathrm{eV}$ ). This indicates that the PL emission in S-GaNP/GaNP does not originate solely from band-to-band radiative emission from the $\mathrm{GaN}_{\mathrm{y}} \mathrm{P}_{1-\mathrm{y}}$ shell, but also represents thermal activation of the $\mathrm{GaN}_{\mathrm{x}} \mathrm{P}_{1-\mathrm{x}}$ core emission. More specifically, apart from activation of band-to-band recombination in the $\mathrm{GaN}_{\mathrm{y}} \mathrm{P}_{1-\mathrm{y}}$ shell, increase in temperature also activates the weak PL component from the $\mathrm{GaN}_{\mathrm{x}} \mathrm{P}_{1-\mathrm{x}}$ core peaking at $\sim 2.05 \mathrm{eV}$ at $300 \mathrm{~K}$. This PL component from the $\mathrm{GaN}_{\mathrm{x}} \mathrm{P}_{1-\mathrm{x}}$ core is $\sim 0.1 \mathrm{eV}$ higher than the band-to-band emission from the $\mathrm{GaN}_{\mathrm{y}} \mathrm{P}_{1-\mathrm{y}}$ shell. The combination of both recombination contributes to a larger blue shift of S-shape behavior of SGaNP/GaNP.

A number of areas, not within the scope of this paper, require further research for this $\mathrm{GaN}_{\mathrm{x}} \mathrm{P}_{1-\mathrm{x}} / \mathrm{GaN}_{\mathrm{y}} \mathrm{P}_{1-\mathrm{y}}$ core/ shell nanowire solar cell: for example, the growth condition for higher $\mathrm{N}$ incorporation, the geometry of the nanowires, including the density, distribution and length of nanowires, and solar cell design and fabrication. Our ongoing efforts and results on $\mathrm{GaN}_{\mathrm{x}} \mathrm{P}_{1-\mathrm{x}} / \mathrm{GaN}_{\mathrm{y}} \mathrm{P}_{1-\mathrm{y}}$ core/shell nanowirebased solar cell will be reported in subsequent papers.

In summary, vertical self-catalyzed $\mathrm{GaN}_{\mathrm{x}} \mathrm{P}_{1-\mathrm{x}}$ nanowires and $\mathrm{GaN}_{\mathrm{x}} \mathrm{P}_{1-\mathrm{x}} / \mathrm{GaN}_{\mathrm{y}} \mathrm{P}_{1-\mathrm{y}}$ core/shell nanowires were grown on $\mathrm{Si}$ (111) by GSMBE. $\mathrm{GaN}_{\mathrm{x}} \mathrm{P}_{1-\mathrm{x}}$ nanowires were grown on top of seeding nano-roots of $\mathrm{GaP}$. The growth window of $\mathrm{GaN}_{\mathrm{x}} \mathrm{P}_{1-\mathrm{x}}$ nanowires was from $\sim 585^{\circ} \mathrm{C}$ to $\sim 615^{\circ} \mathrm{C}$. The shells were grown by decreasing $\mathrm{T}_{\text {sub }}$ and increasing the $\mathrm{V} / \mathrm{III}$ incorporation ratio to reduce adatom mobility and increase $\mathrm{N}$ incorporation. From TEM images, the crystal 
structure of $\mathrm{GaN}_{\mathrm{x}} \mathrm{P}_{1-\mathrm{x}}$ nanowires is a mixture of cubic $\mathrm{ZB}$ phase and hexagonal WZ phase along the [111] growth direction. With regard to optical properties, the PL emission of $\mathrm{GaN}_{\mathrm{x}} \mathrm{P}_{1-\mathrm{x}} / \mathrm{GaN}_{\mathrm{y}} \mathrm{P}_{1-\mathrm{y}}$ core/shell structures exhibits $\mathrm{S}$ shape dependence of the PL peak position as a function of temperature. At low temperature, the emission originates from N-related localized states below the conduction band edge in the shell layer and features a red shift of the PL peak as temperature increases. At high temperature, the emission is from (i) band-to-band radiation recombination in the shell layer and (ii) PL emission from the core layer which has a higher energy than the band edge in the shell layer.

Financial support provided by the National Science Foundation under Grant Nos. DMR-0907652 and DMR1106369 and the Royal Government of Thailand Scholarship (DPST) is greatly appreciated. The PL experiments are supported by the Swedish Research Council (Grant No. 6212010-3815). The TEM experiments are supported by the National Science Foundation of Korea (NRF) and the Korea Government (No. 2013R1A1A1007978), and the Ministry of Trade, Industry and Energy (MTIE) through the industrial infrastructure program under Grant No. 10033630.

${ }^{1}$ C. Lin and M. L. Povinelli, Opt. Express 17, 19371 (2009).

${ }^{2}$ J. Zhu, Z. F. Yu, G. F. Burkhard, C. M. Hsu, S. T. Connor, Y. Q. Xu, Q. Wang, M. McGehee, S. H. Fan, and Y. Cui, Nano Lett. 9, 279 (2009).

${ }^{3}$ B. M. Kayes, H. A. Atwater, and N. S. Lewis, J. Appl. Phys. 97, 114302 (2005).

${ }^{4}$ S. Ke, A. Kargar, P. Namsoek, K. N. Madsen, P. W. Naughton, T. Bright, Y. Jing, and D. Wang, IEEE J. Sel. Top. Quantum Electron. 17, 1033 (2011).

${ }^{5}$ J. M. Spurgeon, S. W. Boettcher, M. D. Kelzenberg, B. S. Brunschwig, H. A. Atwater, and N. S. Lewis, Adv. Mater. 22, 3277 (2010).

${ }^{6}$ C. H. Henry, J. Appl. Phys. 51, 4494 (1980).

${ }^{7}$ W. Shan, W. Walukiewicz, K. M. Yu, J. Wu, J. W. Ager, E. E. Haller, H. P. Xin, and C. W. Tu, Appl. Phys. Lett. 76, 3251 (2000).

${ }^{8}$ W. G. Bi and C. W. Tu, Appl. Phys. Lett. 69, 3710 (1996).

${ }^{9}$ S. Miyoshi and K. Onabe, Solid State Electron. 41, 267 (1997).
${ }^{10}$ P. Pichanusakorn, Y. J. Kuang, C. Patel, C. W. Tu, and P. R. Bandaru, Phys. Rev. B 86, 085314 (2012).

${ }^{11}$ P. Pichanusakorn, Y. J. Kuang, C. J. Patel, C. W. Tu, and P. R. Bandaru, Appl. Phys. Lett. 99, 072114 (2011).

${ }^{12}$ Y. J. Kuang, K. M. Yu, R. Kudrawiec, A. V. Luce, M. Ting, W. Walukiewicz, and C. W. Tu, Appl. Phys. Lett. 102, 112105 (2013).

${ }^{13}$ R. Kudrawiec, A. V. Luce, M. Gladysiewicz, M. Ting, Y. J. Kuang, C. W. Tu, O. D. Dubon, K. M. Yu, and W. Walukiewicz, Phys. Rev. Appl. 1, 034007 (2014).

${ }^{14}$ H. P. Xin, C. W. Tu, Y. Zhang, and A. Mascarenhas, Appl. Phys. Lett. 76, 1267 (2000).

${ }^{15}$ I. A. Buyanova, G. Pozina, J. P. Bergman, W. M. Chen, H. P. Xin, and C. W. Tu, Appl. Phys. Lett. 81, 52 (2002).

${ }^{16}$ G. Letay and A. W. Bett, Proceedings Of the 17th European Photovoltaic Solar Energy Conference Exhibition, Munich, 2001.

${ }^{17}$ S. Sukrittanon, Y. J. Kuang, and C. W. Tu, J. Vac. Sci. Technol. B 31, 03C110 (2013).

${ }^{18}$ Y. J. Kuang, S. Sukrittanon, H. Li, and C. W. Tu, Appl. Phys. Lett. 100, 053108 (2012).

${ }^{19}$ Y. J. Kuang, S. W. Chen, H. Li, S. K. Sinha, and C. W. Tu, J. Vac. Sci. Technol. B 30, 02B121 (2012).

${ }^{20}$ M. C. Plante and R. R. LaPierre, J. Appl. Phys. 105, 114304 (2009).

${ }^{21}$ W. K. Burton, N. Cabrera, and F. C. Frank, Philos. Trans. R. Soc., A 243, 299 (1951).

${ }^{22}$ R. S. Wagner and W. C. Ellis, Appl. Phys. Lett. 4, 89 (1964).

${ }^{23}$ P. Caroff, J. Bolinsson, and J. Johansson, IEEE J. Sel. Top. Quantum Electron. 17, 829 (2011).

${ }^{24}$ I. Vurgaftman, J. R. Meyer, and L. R. Ram-Mohan, J. Appl. Phys. 89, 5815 (2001).

${ }^{25}$ I. A. Buyanova, G. Y. Rudko, W. M. Chen, H. P. Xin, and C. W. Tu, Appl. Phys. Lett. 80, 1740 (2002).

${ }^{26}$ G. Y. Rudko, I. A. Buyanova, W. M. Chen, H. P. Xin, and C. W. Tu, Appl. Phys. Lett. 81, 3984 (2002).

${ }^{27}$ Y. P. Varshni, Physica 34, 149 (1967).

${ }^{28}$ I. A. Buyanova, W. M. Chen, and C. W. Tu, Solid State Electron. 47, 467 (2003).

${ }^{29}$ A. Polimeni, M. Capizzi, M. Geddo, M. Fischer, M. Reinhardt, and A. Forchel, Appl. Phys. Lett. 77, 2870 (2000).

${ }^{30}$ L. Grenouillet, C. Bru-Chevallier, G. Guillot, P. Gilet, P. Duvaut, C. Vannuffel, A. Million, and A. Chenevas-Paule, Appl. Phys. Lett. 76, 2241 (2000).

${ }^{31}$ M. Merrick, S. A. Cripps, B. N. Murdin, T. J. C. Hosea, T. D. Veal, C. F. McConville, and M. Hopkinson, Phys. Rev. B 76, 075209 (2007).

${ }^{32}$ A. Dobrovolsky, J. E. Stehr, S. L. Chen, Y. J. Kuang, S. Sukrittanon, C. W. Tu, W. M. Chen, and I. A. Buyanova, Appl. Phys. Lett. 101, 163106 (2012).

${ }^{33}$ A. Dobrovolsky, S. Chen, Y. Kuang, S. Sukrittanon, C. W. Tu, W. M. Chen, and I. A. Buyanova, Nanoscale Res. Lett. 8, 239 (2013). 